This item was submitted to Loughborough's Research Repository by the author.

Items in Figshare are protected by copyright, with all rights reserved, unless otherwise indicated.

\title{
Competitive intelligence embeddedness: Drivers and performance consequences
}

PLEASE CITE THE PUBLISHED VERSION

https://doi.org/10.1016/j.emj.2019.04.003

PUBLISHER

(c) Elsevier

VERSION

AM (Accepted Manuscript)

\section{PUBLISHER STATEMENT}

This paper was accepted for publication in the journal European Management Journal and the definitive published version is available at https://doi.org/10.1016/j.emj.2019.04.003.

LICENCE

CC BY-NC-ND 4.0

\section{REPOSITORY RECORD}

Markovich, A., K. Efrat, D.R. Raban, and Anne Souchon. 2019. "Competitive Intelligence Embeddedness: Drivers and Performance Consequences”. Loughborough University. https://hdl.handle.net/2134/37580. 


\title{
Competitive Intelligence Embeddedness: Drivers and Performance Consequences
}

\begin{abstract}
The proliferation of Web-based information sources and social media draw firms' attention to these channels as sources of competitive intelligence (CI). To date, research has focused mainly on information collection techniques rather than on CI uses and its influence on firm performance. We define CI embeddedness as the extent to which management and employees incorporate $\mathrm{CI}$ in daily routines, so that actionable knowledge is transferred throughout the organization. A survey of 124 decision makers reveals positive impact of Web CI sources as well as alliances with information providers on CI embeddedness. Furthermore, while CI embeddedness shows no direct influence on firms' performance, it has a mediated effect on performance through customer satisfaction.
\end{abstract}

Keywords: competitive intelligence embeddedness, Web sources quality, information use, performance, 


\section{Introduction}

Competitive intelligence $(\mathrm{CI})$ is a process that produces and disseminates actionable information from and about the firm's external and competitive environments in order to help managers in decision-making and to achieve a competitive advantage (De Almeida et al., 2016). By affecting decision-making, CI bears substantial impact on firms' operations and performance (Ahearne et. al., 2013), yet most research focuses on the intrinsic functionalities of CI (e.g., information gathering and analysis techniques), neglecting to examine the importance of embedding these functionalities throughout the entire firm. CI's contribution to the organization is affected by decision-makers' awareness and acceptance of CI and by a culture of competitiveness (e.g. employee involvement and management support which establishes legitimacy and importance, Saayman et al., (2008)). Indeed, Calof and Wright (2008) emphasize that CI will help firms develop a competitive advantage when the entire organization and its networks commit to developing actionable insights. Such an organizational commitment once reached, acts as a capability translating information into unique know-how (Guanyu and Guocan, 2010; Pemberton and Stonehouse, 2000). The Resource-Based View of the firm defines a capability as an organizationally-embedded nontransferable firm-specific resource whose purpose is to improve the productivity of the other resources possessed by the firm (Makadok, 2001). In a similar vein, previous research suggests that, in today's knowledge-intensive age, when firms are confronted with larger volumes of competitive information and have to sort the relevant information to act on in decision-making, the competitive intelligence process is a capability likely to hold a key role in developing competitive advantages (Rouach and Santi, 2001). By extension, the embeddedness of competitive intelligence throughout the organization is a non-negligible capability. As such, it requires managerial attention and awareness (Fleisher et al. 2008). Therefore, we propose that CI embeddedness (CIE) capability, defined as the extent to which 
CI permeates the entire organization so that strategic and tactical decisions can be made in the knowledge of all relevant external competitive information, plays a key role in affecting organizational performance.

CI research has grown in the last twenty years, relying to some extent on research endeavors in the field of Web competitive data (Du Toit, 2015; He et al. 2015). Yet, these studies tend to concentrate on Web data collection techniques (Rouach and Santi, 2001; Du Toit, 2003; Vaughan and You, 2011), therefore less acknowledging the different types of routinized use of the data being collected (Lackman et. al, 2000), and how this use impacts the evolvement of CI-related organizational culture. Furthermore, while the quality of Web information sources and its impact on firm performance has been addressed to some extent (Rakthin et. al., 2016), an investigation of the potential impact of such quality on CI organizational culture is lacking. Due to the central contribution of CIE to organizations' performance, a deeper investigation of these neglected aspects is called for.

Building on the knowledge management framework, and in line with previous findings (Ho, 2008), this study is an empirical examination of how the perceived quality of Web competitive information sources, and action-oriented uses of that information by managers, impact CIE capability, and how, in turn, CIE affects firms' performance. The rationale for this paper is based on two key points. First, there is evidence that decisionmakers' preferred information sources have traditionally been informal; they are those that come directly from the market (including customers, competitors, and suppliers alike) and are free, rather than coming from formal and expensive commissioned market research, for example (Souchon and Diamantopoulos, 1999). In today's modern, digitalized world, Web information sources stand for another form of cheap informal information collection, and are therefore becoming increasingly popular. New competitive information channels are constantly being developed: digital journalism, search engines, social networks, blogs, 
forums, YouTube and competitors' websites (Chen et al., 2002; Li and Li, 2013), which make information searching quicker, cheaper, and easier than ever before. Due to the unique characteristics of Web information sources (e.g. ease of use, accessibility, relevance, reduced cost, etc.), firms currently rely heavily on Web sources in their decision-making processes and this trend will probably consolidate in the years to come (Fleisher, 2008; Smith and Wong, 2016). Firms are relying on information retrieved from such sources on a daily basis, and there is an increase in the number of firms maintaining an internal unit dedicated for the collection, analyzing and disseminating web information. In the words of Herrera-Viedma, 2006, p. 538), "we can assert that the World Wide Web is the largest available repository of data with the largest number of visitors searching for information. The World Wide Web is a distributed, dynamic, and rapidly growing information source". Surprisingly, while online information sources have been reasonably well studied in the context of consumer decisionmaking (e.g., Chen et al., 2016), this is not the case for organizational decision-making. Webbased sources of competitive information have so far stimulated relatively little empirical research interest, although competitive information can be found in abundance on the Internet as early as 1996 (Benczúr, 2005; du Toit, 2015).

Secondly, while one might wonder what the distinctions are between online and analog information sources, that warrant specific studies for the former, there are, in fact, challenges associated with web information sources that make their study particularly pertinent. As explained above, traditionally, competitive information was collected from wellknown and trusted sources, such as personal contacts. Today, on the other hand, much more information gathering is based on faceless digital sources (e.g. websites, social media). Combined with the fact that volumes of information are increasing, potentially contributing to information overload (Saxena and Lamest, 2018), quality is becoming a major criterion for distinguishing between usable and redundant information. Yet, and again surprisingly, 
"existing research has still largely ignored the quality of market information that is a crucial issue in the era of an information society" (Dabrowski, 2018, p. 115). This makes our study particularly pertinent for all organizations handling and using web-sourced competitive information.

This study's contribution is twofold. First, we introduce CIE capability as a manifestation of CI-related organizational culture aspects while addressing its impact on firms' performance. Second, we address the impact of different information uses, and the level of information source perceived quality as antecedents to CIE.

In the next section we discuss CIE in the context of the knowledge management framework, addressing information use and perceived source quality and their impact on CIE. We proceed by addressing two aspects of firm performance to assess the effect of CIE. Next, we outline our methodology and provide findings using SEM-based path analysis. We conclude by discussing our findings, main contributions and future research.

\section{Literature Review}

Bernhardt (1994) defines CI as "an analytical process that transforms disaggregated competitor, industry, and market data into actionable strategic knowledge about the competitor's capabilities, intentions, performance, and position" (p. 13). As such, it is an interpretive process that focuses on competitive environmental factors that affect the firm, and is hence crucial to firms' competitive advantage and success (Mariadoss et al. 2014). By contrast, Business Intelligence refers to a collection of technologies aimed at collecting, extracting and analyzing a variety of performance metrics, while relying on enterprisespecific data (Chen et al. 2012; Torres et al., 2018). The two are therefore complementary but distinct. 
The CI process is known as the "intelligence cycle" and includes four phases: planning, collection, analysis and communication of intelligence (Nasri, 2011). The first CI cycle's phase, planning, determines the intelligence needs of the decision makers, and the information required to generate the needed intelligence. This phase is important to define the necessary resources of information (Saayman et al., 2008). The second phase, collection of competitive information, is done in various methods. According to Rouach and Santi (2001), information that can be obtained legally and ethically is divided into two categories: publicly available information (newspapers, databases and the Internet) and specialized information such as from exhibitions and professional publications. The third phase relates to the interpretation and translation of collected raw data into actionable intelligence by using analytical tools. Finally, the fourth phase relates to the communication of the CI results to those with the authority and responsibility to act on it, by using presentations, periodic reports and so on (Nasri, 2013; Saayman, 2008).

We claim that actual implementation of the CI cycle to its full potential depends on the development of CIE as a capability in the firm. CIE refers to the extent to which CI permeates the entire organization so that strategic and tactical decisions can be made in the knowledge of all relevant external, competitive, information. Previous research shows that if $\mathrm{CI}$ is well embedded in the firms' culture, there is a higher probability that the CI activities will be supported and used in all its phases (Saayman, 2008). A firm's acknowledgement of CI importance, accompanied by a supportive organizational culture, contributes to the successful utilization of CI (Sinkula, 1994; Slater and Narver, 2000; Ardito and Petruzzelli, 2017;). This is achieved by senior management engagement, which gives legitimacy and importance to CIbased processes. Nasri (2011) suggests that the existence of such engagement coupled with culture and structure which encourage trust, facilitate communication and easy flow of information, has important contribution to successful competitive intelligence activity. 
Looking at it from a failure prism, Fleisher and Wright (2008) advocated for managerial level accountability for CI to achieve its goals by providing a suitable organizational environment. Evgeniou and Cartwright (2005) concluded that "the ability to successfully search, assemble all pieces, analyze, and effectively use all relevant available information" (p. 298) should be considered as an organizational capability. Drawing from this, the main components of CIE are: appropriate policies, procedures and desirable process. These components are complimented by internal intelligence reports, and ongoing engagement of senior and midlevel management as well as employees (Saayman et al., 2008). These assertions were operationalized in the current study (See appendix).

CIE emphasizes the incorporation of information for internal creation of knowledge and improved performance hence can be addressed within the knowledge management framework (Moustaghfir, 2009). Yet, since CIE is fueled by information, we can assume that information quality will have an impact on its implementation. This is supported by Gorla et al. (2010) who established that information quality has a positive impact on organization performance, and Kyoon (2014) who found an impact of perceived quality on innovativeness. Similarly, Setia et al. (2013) found a direct link between Web information quality and firms' capabilities and performance. Furthermore, use of information by decision-makers was previously found to have an impact on firms' performance (Souchon et al., 2003). Considering that CIE is based on intra-organization information use, it is crucial to explore the types of use supporting the establishment of CIE. In the following section we discuss and hypothesize the relationship of Web information sources' quality, and the different types of information use, with CIE.

Web information sources' perceived quality and CIE 
The development of the Web has stimulated the creation of a new world of accessible and available competitive information sources external to organizations, which enrich especially the collection phase of the CI (Leeflang et al. 2014; Reinmeoller and Shaz, 2016; Sher and Lee, 2004). New competitive information channels are constantly being developed: digital journalism, search engines, social networks, blogs, forums, YouTube and competitors' websites (Chen et al., 2002; Li and Li, 2013), which make information searching quicker, cheaper, and easier than ever before. Due to the unique characteristics of Web information sources (e.g. ease of use, accessibility, relevance, reduced cost, etc.), firms currently rely heavily on Web sources in their decision-making processes and this trend will probably consolidate in the years to come (Fleisher, 2008; Smith and Wong, 2016). Surprisingly, while online information sources have been reasonably well studied in the context of consumer decision-making (e.g., Chen et al., 2016), this is not the case for organizational decisionmaking. Web-based sources of competitive information have so far stimulated relatively little empirical research interest, although competitive information can be found in abundance on the Internet as early as 1996 (Benczúr, 2005; du Toit, 2015). The Web influenced all four stages of the CI cycle - planning, collecting, analyzing, and communicating, (Ferrara et al. 2014). By providing the information and the means to collect, analyze and distribute it in a cost-effective manner, the Web opened the world of CI to smaller and resource-constrained firms, thus bridging new markets and activities for them (Tarraf and Molz, 2006). But the opportunity provided by Web information sources also embodies a threat. The growing volume of information necessitates the development of a screening process to avoid information overflow. Therefore, in order to balance the costs associated with information screening, firms must evaluate the benefits arising from the Web CI. One such benefit is the quality of the information retrieved (Isik et al., 2013). Previous research shows that the Internet had a positive impact on the quality of competitive information, which had positive 
impact on the organization by improving three strategic benefits: revenue generation, cost reduction and managerial effectiveness (Raghunathan, 1999; Teo and Choo, 2001). However, to be embedded in corporate culture, quality of information must be perceived as such by managers. Hence, it is of great importance to understand how this perceived quality of Web competitive information sources, such as job sites, social networks and discussion groups, and information sources and analyzed data obtained from service providers (See appendix), affects the development of CIE within firms.

Hypothesis H1: Perceived quality of Web information sources is positively related to competitive intelligence embeddedness

\section{Information action-oriented uses and CIE}

Action-oriented information use refers to the use of information in the decision-making process that causes changes to the user's activities (Menon and Varadarajan, 1992). Actionoriented use of information has two dimensions - the first is the use of information in a manner that is consistent with the intent and implications of the information collected, the second is use that deviates from the original intent and implications, and therefore is considered as biased. While the former received substantial research attention, the latter is less explored although it bears potential significant impact on firms' operations and performance (Rollins, Bellenger and Johnston, 2012). Following Menon and Varadarajan's (1992) theoretical model, and in line with previous research (Rollins, Bellenger and Johnston, 2012), we focus on this deviated and biased dimension of information use while aiming to explore its influence on firms' performance through CIE.

Action-oriented biased uses of information occur on various occasions. The first type refers to situations when managers use information to make the information suppliers (i.e. consultants, Web monitoring companies, media monitoring companies) feel included in the 
decision-making process, in order to maintain positive relationships with them (Menon and Varadarajan, 1992). The need for this type of use arises out of cultural differences and potential conflicts between information suppliers and users (Dunn, 1986). External information providers are considered central to the information gathering process mainly due to their control over the quality of the information provided. Such control can often determine the quality of the decision making process (Toften and Rustad, 2005). With increased trust between the information users and providers, it may be expected that information being provided will be more up-to-date and relevant to decision-making needs (Kim, Ferrin, and Rao, 2008; Vyas and Souchon, 2003). Hence, the strength of the relationship with information providers will enhance the development of the CIE in the organization. We operationalized these into five items capturing the essence of the relationship aspects (See appendix).

\section{Hypothesis H2a: The strength of the organization's relationship with information} providers is positively related to competitive intelligence embeddedness.

The second type of information biased use occurs when decision makers use information or avoid disseminating information, in order to improve employee morale or impact employees' actions (Menon and Varadarajan, 1992). This is often manifested by encouraging salesmen, or other employees in the firm, through manipulation of the information used. The information is used not necessarily for its value but because it sends a positive message within the firm. This also occurs when portraying a positive picture within the firm, to hide or distort negative information, or to justify an existing bias (e.g. Russo et al., 2008). A possible explanation for such behavior comes from perceiving information as a trigger for change. In cases when specific information might cause a negative change (e.g. in the behavior of employees) the information itself can be faced with resistance (Oreg, 2006). Therefore, by refraining from deploying and using such information managers can motivate behavior or avoid a perception 
of change. This attitude was incorporated in the items measuring resistance to information (See appendix). Hence, information resistance stands in contrast to CIE, therefore:

Hypothesis $\mathbf{H} 2 \boldsymbol{b}$ : Resistance to information is negatively related to competitive intelligence embeddedness.

The third type of biased information use, information inaccuracy, refers to situations when the decision-makers distort the information obtained, or take it out of context. This distortion is operationalized in the three items capturing information inaccuracy (See appendix). This kind of use is sometimes hard to define, since "as more information becomes available, it is increasingly easier to 'prove' what one wishes" (Hogarth and Makridakis, 1981, p. 557). Vyas and Souchon (2003) suggested negative relations between this type of distorted use and performance, due to the receiver reaction to the distorted information. Similarly, BettisOutland (1999) claimed that distorted information, if perceived as such by the information users, will lead to a potentially negative impact on firms' strategy. Therefore, we can assume negative relationship between inaccuracy and embeddedness.

Hypothesis H2c: Information inaccuracy is negatively related to competitive intelligence embeddedness.

The fourth type of biased information use is for creating or maintaining political bases within the organization (Menon and Varadarajan, 1992, p. 62). The meaning is that information is used in order to gain power within the firm, with less regard, if at all, for the real meaning of the competitive information (Beyer and Trice, 1982; Ulijn and Brown, 2004). This political use of information is captured in four items (See appendix). This type of use may contradict the positive effects of organizational learning (Sinkula, 1994) and a firm's accumulated knowledge (Knight and Cavusgil, 2004). Previous research showed how unequal distribution 
of information between decision makers impacts decision quality negatively (McCardleKeurentjes, Rouwette and Vennix, 2008), Thus:

Hypothesis H2d: Political use of information is negatively related to competitive intelligence embeddedness.

The perception of quality of information sources by managers and the uses of information within companies are antecedents of CIE. The following sections establish the hypothesized links between CIE and outcomes, specifically customer satisfaction and overall perceived performance.

\section{Customer satisfaction}

Customer satisfaction is defined as an evaluation of the customer's overall purchase and consumption experience with the firm, over time (See appendix). It was previously found to have a strong and positive linkage with different performance-related aspects such as customer retention and customer loyalty (Anderson, Fornell and Mazvancheryl, 2004). Customer satisfaction is also a key component in the creation of brand equity (Torres and Tribo, 2011) and firms' reputation (Dominici and Guzzo, 2010). It is manifested through the increase in customers' re-use of services and products (Williams and Naumann, 2011), along with their willingness to recommend the consumed products or services to other potential customers, leading to a positive word-of-mouth effect (Kim, $\mathrm{Ng}$ and $\mathrm{Kim}, 2009$ ).

According to Margulies (1997), competitive actions in the market place require a focus on meeting customer requirements, and the ultimate goal of any competitive intelligence process is to raise customer satisfaction to improve organizational performance (Baker and Sinkula, 2009). Thus, much of the competitive intelligence obtained and acted on by organizations has the customer at its center. This is the premise of the rich body of work 
on market orientation, originating as early as the 1990s (e.g., Kohli and Jaworski, 1990; Narver and Slater, 1990). Thus, we expect the following:

Hypothesis H3: Competitive intelligence embeddedness is positively related to customer satisfaction.

\section{Overall performance}

$\mathrm{CI}$, incorporated in the market orientation framework, was singled out for its impact on firm's performance, either directly or through different mediators. CI was found to have a direct impact on marketing performance (Aheame et al. 2013; Hughes, Le Bon, and Rapp, 2012), as well as overall firm performance (Johns and Van Doren, 2010). Such performance is measured through indicators such as growth, turnover, positioning, and expectations (See appendix). Previous research also addressed it as an antecedent to marketing capabilities and competitive advantage (Murray, Gao, and Kotabe, 2011). Hence:

Hypothesis H4: Competitive intelligence embeddedness is positively related to firm performance.

Figure 1 summarizes the variables and the relationships among them as described so far in the hypotheses. Next, we describe the study design and various scales used to assess the constructs.

Insert Figure 1 here

\section{Methodology}

Study design 
The data for this study was collected in Israel by using a cross-sectional survey of mid-level and senior managers, all regarded as experts in the field of CI and knowledgeable regarding CI in their firms (Floyd and Woolbridge, 1997 ; Wilson and Lilien, 1992). The sampling frame included firms that employ at least 10 employees, and have annual sales of at least one million dollars. Due to the challenging task of both reaching the appropriate managers as well as convincing them to reveal information regarding their firms, sampling was carried out in two stages - First we approached CI managers who are members of the "Israeli Competitive Intelligence Forum”, The approach was made via the LinkedIn of the forum and produced 36 responses. Second, we approached additional firms by cross-referencing several sources of information: Dun \& Bradstreet's Database of Israeli companies, Coface BDI ranking the 500 leading companies in Israel, list of members of the Kibbutz Industries Association, TASE (Tel Aviv stock exchange) companies list and Israel Ministry of Industry and Trade major exporters list (2005). We screened out firms with no clear CI function and then approached the relevant managers first by phone and then by email containing the link to our questionnaire. Data was collected between April and June 2015, through self-report Webbased questionnaires. The constructs were first translated to Hebrew and then back translated. The two versions were screened by a third author who is fluent in both languages to identify and correct any divergence in meanings. The questionnaire was sent to 407 people, out of which 124 responded (response rate $=30.5 \%$ ). Of the 124 participants, $68 \%$ were senior managers: $14 \%$ CEOs, $31 \%$ division managers, $23 \%$ marketing managers or related fields. The other $32 \%$ included $20 \%$ mid-level managers and $12 \%$ senior consultants in various management disciplines. All respondents held at least 5 years of experience in their current positions and all engaged in CI activities on a regular basis, both from the strategic decisionmaking aspect and from the tactical day-to-day operations, supporting Wilson and Lilien's (1992) condition for using single informants. 
The sample included both small and medium sized (SMEs), and large corporations. $68 \%$ of the firms adhere to the SME definition - $31 \%$ having an annual turnover of less than $€ 5 \mathrm{~m}, 36 \%$ with $€ 5-50 \mathrm{~m} .31 \%$ of the firms presented indicators (No. of staff $>250$ and turnover $>5 \mathrm{O} \mathrm{m}$ ) which qualified them as large corporations according to the European Commission (2016) criteria.

Since our data came from two separate approaches, we tested for differences between the two datasets based on the main constructs. No statistically significant differences were found indicating that the datasets could be analyzed as one.

\section{Operationalization}

All of the measures were adapted from existing scales in business literature and were based on 1-7 likert scales. CIE and the action-oriented biased information use scales were adapted to the CI field (see appendix for full questionnaire and item loadings).

Web sources' perceived quality, included 7 items from Teo and Choo (2001) referring to the level of quality associated with the different web information sources. A factor analysis revealed that the 7 types of sources referred to in the items are divided into two groups titled as Analyze for a group of four sources representing analyzed information or information that is fertile ground for analysis and Formal for three sources that are official materials or based on official information.

Performance, measured three years' effectiveness indicators, with five items sourced from existing scale (Zou, Taylor, and Osland 1998) $(\alpha=0.877)$, capturing growth and improvement.

Customer satisfaction, relates to indices such as loyalty and complaints, based on three items (Katsikeas et al., 2006; Hooley et al., 2005; Vijande et al, 2012) $(\alpha=0.865)$. 
$C I E$ - refers to the incorporation of CI awareness and processes in the firm, e.g. distribution of reviews on competitors and managers' awareness of CI's importance. The CIE scale included four items based on Saayman et al (2008), Wright and Calof (2006), Adidam et al. (2012), GIA (2005), and Singh \& Beurschgens A. (2006) $(\alpha=0.872)$. A preliminary stage of talks with three CI senior managers in different fields was taken in order to screen and incorporate the relevant items from the sources listed here for the scale. Each item was validated by the managers prior to it being used in the questionnaire.

The next set of constructs relate to the various action-oriented biased information use, and are adapted from an existing scale (Korobilis-Magas, 2010). Information Use Alliance scale includes five items $(\alpha=0.946)$, all referring to the relationships developed between the information users and providers. Information resistance scale includes three items $(\alpha=0.822)$ and refers to internal resistance to information use. Information inaccuracy scale consists of three items $(\alpha=0.866)$ which describe the tendency to use the information retrieved inaccurately. Information political use scale consists of four items $(\alpha=0.796)$ and describes the tendency to use information for political gains. See appendix for detailed information on items and loadings.

Finally, three control variables were included in the study - firm size in terms of number of employees and sales, and firms' age. Table 1 displays the descriptive statistics for all variables measured.

\section{Insert Table 1 here}

Before testing the hypotheses, we conducted two separate tests for limiting common method variance (CMV). First, we used the Harman single-factor test, and found no common factor arising from the data. Second, we tested for CMV through the marker variable technique (Lindell and Whitney, 2001; Malhotra, Kim, and Patil, 2006), using social desirability of the 
respondents as a marker. Comparing the original CFA results to the CMV-adjusted CFA, we found no significant difference in model fit; therefore, CMV is not likely to explain any of the relationships found among the constructs.

\section{Findings}

The hypotheses were tested by Structural Equation Modeling (SEM), using the statistical software AMOS, to examine to what extent do the perceived quality of information extracted from Web sources and the information process-related variables explain CIE in the firms, as well as, how this embeddedness influences performance of the firm through customer satisfaction. The perceived quality of Web information sources was divided into Analyze and Formal. Fit indices are presented in Table 2.

Insert Table 2 here

The results for the hypotheses tests are presented in Table 3.

Insert Table 3 here

The model explains $30 \%$ of the variance in CIE, while CIE explains $14 \%$ of the variance in customer satisfaction, and both explain $22 \%$ of the variance in overall performance.

The results of the hypotheses tests were as follows. Both groups of Web sources Analyze and Formal, revealed significant positive impact on $\operatorname{CIE~}(\beta=.219, \mathrm{p}<.05 ; \beta=.173$, $\mathrm{p}<.05$ respectively), supporting H1. Information providers' alliances was found to have a positive impact on $\mathrm{CIE}(\beta=.321, \mathrm{p}<.01)$, confirming $\mathrm{H} 2 \mathrm{a} . \mathrm{H} 2 \mathrm{~b}, \mathrm{c}, \mathrm{d}$ were rejected as information resistance, information accuracy and information political use had no statistically significant relation with CIE. H3 was validated as CIE showed the expected positive influence 
on customer satisfaction $(\beta=.309, \mathrm{p}<.01)$. H4 was rejected showing no impact of CIE on firm's performance as perceived by managers.

\section{Post-hoc analysis - Sobel test for mediation}

Following the results regarding the impact of CIE on customer satisfaction, and lack of impact on performance, we tested for the mediation of customer satisfaction on the relationship between CIE and performance, using the Sobel test. Comparing the findings of CIE directly impacting performance $(B=.154)$ vs. its impact, mediated through customer satisfaction $(B=.196)$, Sobel test revealed that the change in impact is significant $(\mathrm{z}$ value $=1.672, \mathrm{Std}=0.018, \mathrm{p}<.10$ ); therefore, we can conclude that partial mediation exists.

\section{Discussion}

This study explores the concept of CIE capability while discussing its drivers in the form of the impact of Web competitive information sources' perceived quality and action-oriented information biased uses. It further investigated the outcomes of CIE in the form of its impact on customer satisfaction and firms' performance. In doing so, this study contributes to existing research by introducing CIE as an organizational capability which evolves from firms' meaningful efforts to substantiate CI related activities. With the growing understanding of the role played by CI in enhancing firms' competitiveness such introduction is long due. The study also addresses the gap presented by the lack of systematic examination of the Web information sources quality. While the development of Web sources of competitive information, revolutionized the world of CI, the discussion on quality of Web sourced CI and its implications received little empirical research interest (Benczúr, 2005).

CIE was developed and examined against the two types of antecedents presented here, contributing significantly to our understanding of how Web information perceived quality, 
and action-oriented biased information uses impact the existence of such embeddedness capability. Given the influence CI holds over firms' performance, identifying the necessary elements enabling the creation of CI-related organizational culture constructs promotes our understanding regarding the role played by CI internally.

The perceived quality of Web information sources, divided into two sub groups analyzed sources, and formal sources, showed a positive impact on CIE, strengthening the original claim as to the use of Web information which is perceived to be of high quality, in the establishment of CIE. As stated earlier, information overflow interferes with the firms' decision making ability, and consequently might damage performance (Gammelgaard and Ritter, 2005). Such overflow often mixes information of different quality levels. Aiming to extract high quality information enables firms to both reduce the volume of information gathered and improve the quality of the decision-making outcomes (Kim, Ferrin and Rao, 2008). The Analyze sub-group of information sources identified in the study as influential relies on information extracted from competitor's sites, social networks and service providers. Thus, it appears that this group of Web sources of information has priority among decisionmakers. Analyzed information sources require a high processing level. It is challenging for decision makers to gather this information in its entirety and understand its implications. Information from social networks and from Web monitoring and analysis service providers, operating Web crawlers in the relevant Web sites, is a challenge to internalize, but is of great importance as it comes in rapidly, before formal publications appear. Moreover, such information, especially from social media sources, is considered to be objective and accurate. As such it bears positive influence on the decision making process and enhances the added value achieved from the CI activity thus supporting the CIE.

Similarly, the Formal sub-group of sources, was identified as influential. It is based on reviews and articles in relevant industry websites, financial statements of the competitors and 
analyses published on competing firms. These sources are perceived as useful for competitive information first because they are official and, by definition, more reliable. Firms check information quality before releasing it to the Web due to the irreversibility of the act and to avoid inconveniences which might occur after publication. In addition, formal information enables competitors to learn about the firm's strategic planning that is often manifested through its financial statements and competitor's analyses. Therefore, formal sources are regarded of high quality, and since they provide semi analyzed information, they contribute to advancing the efficiency of the CI activity which translates into better CIE.

As for action-oriented information biased use, alliances with information providers had positive impact on CIE. The argument for this relies on the core principles of the knowledge management, learning and sharing processes which occur between the partners (Grant and Baden-Fuller, 2004). Indeed, well managed alliances bear significant impact on decision making processes and performance by enhancing the value of the knowledge created and disseminated (Dyer, Kale and Singh, 2001).

As for the types of action-oriented information uses, information resistance, information inaccuracy and political use of information, all three showed no significant impact on CIE. Information resistance, while we hypothesized a negative impact, showed no impact. A possible explanation is based on the conflicting forces associated with information resistance. On the one hand it can trigger an intuitive reaction to information perceived as change, by resisting it (Lapointe and Rivard, 2005). Such a reaction will most likely jeopardize firms' performance. On the other hand, information resistance can be interpreted as the will to shield the firm's performance from potential negative impacts. If so, information resistance in this specific context can be regarded as an internal buffer screening out unwanted information-related effects. In both cases information resistance might inhibit CIE 
but not to the full expression of a negative impact. This line of thought warrants future research.

Information inaccuracy refers to a distorted use of the information by managers, while political use of information aims at providing power base. Both share a common principle of using information primarily to satisfy personal reasons. Possible explanation for both types links them with the information quality reported in regard to the Web information sources. The relatively high level of perceived quality might have compensated for the potential negative impact of both distorted use and the political use on CIE.

Regarding CIE consequences, we found that CIE bears positive impact on customer satisfaction but had no direct impact on performance, while post hoc analysis revealed a mediation effect of CIE on performance through customer satisfaction. These findings align with previous research anchoring performance in CI-related orientation (Kumar et al. 2011). Rouach and Santi (2001) discussed the relevancy of management's role in ensuring the contribution of CI processes to firms' performance, which provides support for our endeavor to link CIE with firms' performance. While previous research paved the link between CI and performance (Mariadoss, et al. 2014; Rapp, Agnihotri and Baker, 2015) a deeper understanding of CI-related organizational capability, termed as CIE was lacking. In this context, the main contribution of the present study in regard to CIE consequences, refers to the relationships between CIE, customer satisfaction, and overall performance. A mediation analysis revealed that the impact of CIE on performance weakens once customer satisfaction is introduced into the model, showing that the latter partially mediates the impact of the former. This finding implies that CI's influence on performance comes partially from improving customer satisfaction levels which, in turn, impact performance.

Customer satisfaction is considered to be an important aspect of firms' performance, due to the growing awareness surrounding the role customers play in creating value for firms 
(Gomez, McLaughin, and Wittink, 2004; Prabhakaran and Satya, 2003). Previous research claimed that customer satisfaction affected different aspects of financial performance (Ittner and Larcker 1998; Anderson, Fornell, and Mazvanchery, 2004), as well as future performance (Banker and Mashruwala, 2007). Firms with high customer satisfaction rely on intimate relationships built with customers. These relationships build the "reputation" of the firm over time (Anderson and Yu, 2015). Favorable reputation leads to sustained superior financial performance (Carter and Ruefli, 2006).

The present findings establish CIE as an important factor in enhancing customer satisfaction. This outcome draws from the essence of CI, offering market information. As pointed out earlier, CI provides an overall screening of the firm's environment, yet its main goal is to improve the firm's competitive positioning. As such CI places the customer in the center of attention (Hughes, Le Bon and Rapp, 2013). Our study complements previous findings by showing that a well-established CIE improves customer satisfaction first and foremost, and through it firms' performance. Furthermore, our study reveals the central role alliances with information providers play in enhancing the internal organizational aspects which contribute to CIE establishment.

Last, we should acknowledge CIE as a capability. Eisenhardt and Martin (2000) define a capability as processes that integrate and reconfigure resources to create value and achieve competitive advantage. CIE fit well with this description as it is process-based and relies on the information use as "raw material" for the production of added value in the form of customers' satisfaction. This characterization is supported by previous findings grounding CI as a routine that once provided with the suitable acknowledgement will enhance firms' performance (Ho, 2008). 


\section{Managerial implications}

The important practical conclusion arising from our research findings points to the importance of Web competitive information on one hand, and highlights the importance of firm's CIE, on the other hand. First, competition information which can be located on the Internet is perceived as having quite high quality by managers in Israel. Their average and median ratings were about five on a seven-point scale. Second, according to this research, the level of use of resources is differentiated: about a third of the decision makers were not aware of some of the information sources which appeared in the perceived quality questionnaire. Third, the set of the independent variables (perceived quality of Web source and information usage) explains $30 \%$ of the variance in CIE; CIE explains $14 \%$ of the variance in customer satisfaction; and CIE and customer satisfaction together explain $22 \%$ of the variance in overall performance. The notable practical conclusion of these results is the importance of creating and keeping a high level of CI organizational culture.

The way in which CIE capability is enhanced, based on the processes and procedures embedded within the firm, depends primarily on the commitment of the board and senior managers, giving legitimacy and importance to the CI activity within the firm. The ownership of the CI competency should be at a high level in the firm, possibly a member of the board or division manager. Intelligence creates value if it is part of the decision making process (Rodenberg, 2007). Decisions should be made with actionable intelligence (Singh \& Beurschgens, 2006). A high level of CI culture means that the key topics on the competitors are known to headquarters as well as to field levels and, moreover - they all are aware of the importance of information about competitors. Top down processes will necessarily spread across the organization. Managers should rely on Web-based information such as periodic competitor's reviews, daily marketing and competitive newsletter, and so on in their strategic assessments and daily operations. 
Every business organization examines its expenses in terms of cost-benefit. Web data, by definition, is a resource that is available, accessible, usually at modest cost. As a result, in many cases, information is overloaded, some of it is not relevant, making it challenging to extract and utilize the information and refine information in order to support decisions. One possible solution to overload is allocation of resources dedicated to CI, and formation of a routine review of competitive information that replaces distribution of raw competitive data (Gilad, 2015). Allocation of internal organizational resources or contracting external consultants that provide compact and analyzed relevant information would aid in establishing beneficial CI practices.

Firms should strive to learn their relevant Web information sources in order to support CIE and the decision support it entails. Ultimately, firm performance will improve.

\section{Limitations and future research}

Our study targeted senior managers in various industries and fields of expertise, who are involved in CI processes on a daily basis. This data collection provided us with a general understanding of the relationships between perceived information quality, CIE, and organizational performance. Yet, since each industry is characterized by different levels of environmental turbulence, it is expected that CIE will act differently in impacting firms' performance. Therefore, future research could expand on this understanding by exploring, for example, high-technology vs. low-technology industries, and local vs. international firms. In both cases we expect to see differences in CIE' antecedents and consequences due, in part, to the differences in environmental turbulence.

In the present study we used a unidimensional variable for measuring Web information sources' perceived quality, although quality is a multi-dimensional construct. 
Future research should further explore the subject of information quality relating to Web information sources, by examining different aspects of quality such as: accuracy, completeness, importance, reliability, timeliness, and usefulness, as well as possible linkage between the different aspects.

Thirdly, while customer satisfaction appears to be a strong mediator in the CI embeddedness-performance link, the measure used and responses obtained were from the organizations themselves, thus a perception of customer satisfaction. In future, studies on CIE could employ a dyadic approach and collect customer satisfaction data directly from customers.

Fourth, our study focusses on the network of information processing antecedents to CIE development. As such, we examine quality of information sources accessed by the organization and use of the acquired information, following Menon and Varadarajan's 1992 seminal work), as directly contributing to the development of CIE. Further research should expand the nomological network of antecedents to include a broader set of capabilities beyond those information processing-specific variables.

Finally, in our endeavor to establish the concept of CIE, we reached for managers across functions, discovering that in some firms CI activities are performed by a specific unit while in other cases CI is assigned to the marketing/sales divisions. Future research should investigate CIE while comparing organizational contexts.

\section{Conclusion}

The present study introduces the concept of CIE by examining CI-related organizational culture aspects and the perceived quality of types of Web information sources while also exploring the outcomes of this new concept. The findings show that information perceived quality, and alliances with information providers act as antecedents to CIE. We also found 
that by creating CIE, firms improve their performance through enhancing customer satisfaction. Investigating CIE in the flow from information acquisition, through its uses and on to its substantial contribution to performance measures provides fertile ground for cultivating CIE as integral to organizational culture. 


\section{References}

Adidam P.T., Banerjee M., \& Shukla P. (2012). Competitive intelligence and firm's performance in emerging markets: an exploratory study in India. Journal of Business and Industrial Marketing, 27, 242 - 254.

Ahearne, M., Lam, S. K., Hayati, B., \& Kraus, F. (2013). Intrafunctional competitive intelligence and sales performance: a social network perspective. Journal of Marketing, 77 , 37-56.

Anderson, E. W., Fornell, C., \& Mazvancheryl, S. K. (2004). Customer satisfaction and shareholder value, Journal of Marketing, 68, 172-185.

Anderson M., \& Yu Z. J. (2015). Customer Satisfaction, Cost Behavior and Future Performance Canadian Academic Accounting Association (CAAA) Annual, https://ssrn.com/abstract $=2716189$

Ardito, L., \& Petruzzelli, A. M. (2017). Breadth of external knowledge sourcing and product innovation: The moderating role of strategic human resource practices. European Management Journal, 35, 261-272.

Baker, W. E., \& Sinkula, J. M. (2009). The complementary effects of market orientation and entrepreneurial orientation on profitability in small businesses. Journal of small business management, 47, 443-464.

Banker, R. D., \& Mashruwala, R. (2007). The moderating role of competition in the relationship between nonfinancial measures and future financial performance, Contemporary Accounting Research, 24, 763-793.

Benczúr, D. (2005). Environmental scanning: How developed is information acquisition in western European companies?, Information Research, 11. Retrieved from $\underline{w w w . s c o p u s . c o m}$

Bernhardt, D. C. (1994). I want it fast, factual, actionable — tailoring competitive intelligence 
to executives' needs. Long Range Planning, 27, 12-24.

Bettis-Outland, H. (1999). The impact of information distortion within the context of implementing and sustaining a market orientation, Journal of Strategic Marketing, 7, $251-263$

Beyer, J. M., \& Trice, H. M. (1982). The utilization process: A conceptual framework and synthesis of empirical findings, Administrative Science Quarterly, 591-622.

Business Data Israel (BDI) (2015). Ranking the 500 leading companies in Israel 2015 (Hebrew)

Calof, J. L., \& Wright, S. (2008). Competitive intelligence: A practitioner, academic and inter-disciplinary perspective, European Journal of Marketing, 42, 17-730.

Carayannopoulosa, S., \& Austerb, E.R. (2010). External knowledge sourcing in biotechnology through acquisition versus alliance: A KBV approach, Research Policy, $39,254-267$.

Carter M.S., \& Ruefli W.T. (2006). Intra-Industry Reputation Dynamics Under a ResourceBased Framework: Assessing the Durability Factor, Corporate Reputation Review,9, $3-25$.

Chen, H., Chau, M., \& Zeng, D. (2002). CI Spider: a tool for competitive intelligence on the Web, Decision Support Systems, 34, 1-17.

Chen, H., Chiang, R. H., \& Storey. V. C. (2012). Business intelligence and analytics: from big data to big impact, MIS quarterly, 1165-1188.

Chen, J., Teng, L., Yu, Y., \& Yu, X. (2016). The effect of online information sources on purchase intentions between consumers with high and low susceptibility to informational influence. Journal of Business Research, 69, 467-475.

Cloutier, A. (2013). Comoetitive intelligence process integrative model based on a scoping review of the literature, International Journal Of Strategic Management, 13, 57-72. 
Dabrowski, D. (2018). Sources of Market Information, Its Quality and New Product Financial Performance. Engineering Economics, 29, 115-122.

De Almeida, F. C., de Almeida, F. C., Lesca, H., Lesca, H., Canton, A. W., \& Canton, A. W. (2016). Intrinsic motivation for knowledge sharing-competitive intelligence process in a telecom company, Journal of Knowledge Management, 20, 1282-1301.

Dominici, G., \& Guzzo, R. (2010). Customer satisfaction in the hotel industry: A case study from Sicily, International Journal of Marketing Studies, 2, 3-12.

Dun \& Bradstreet (2015), Duns Guide Israel 2015, Tel Aviv: Dun \& Bradstreet (Hebrew)

Dunn, W.N. (1986). Conceptualizing knowledge use, in Beal, G.M. et al. (Eds), Knowledge Generation, Exchange, and Utilization, Westview Press, Boulder, CO.

Du Toit, A. S. A. (2003). Competitive intelligence in the knowledge economy: What is in it for South African manufacturing enterprises?, International Journal of Information Management, 23, 111-120. Retrieved from www.scopus.com

Du Toit, A. S. (2015). Competitive intelligence research: An investigation of trends in the literature, Journal of Intelligence Studies in Business, 5, 14-21.

Dyer, J. H., Kale, P., \& Singh, H. (2001). How to make strategic alliances work, MIT Sloan Management Review, 42, 37-43.

Eisenhardt, K. M., \& Santos, F. M. (2000). Knowledge-Based View: A New Theory of Strategy?, In A. Pettigrew A., Thomas H., and Whittington R. (Eds.) Handbook of Strategy and Management, London: Sage Publications.

European Commission (2016), User guide to the SME definition, Ref. Ares 956541 (accessed on: 3 December, 2018)

Evgeniou, T., \& Cartwright, P. (2005). Barriers to information management. European Management Journal, 23, 293-299. 
Ferrara, E., De Meo, P., Fiumara, G., \& Baumgartner, R. (2014). Web data extraction, applications and techniques: a survey, Knowledge-Based Systems, 70, 301-323.

Fleisher, C. S. (2008). Using open source data in developing competitive and marketing intelligence. European journal of marketing, 42(7/8), 852-866.

Fleisher, C. S., Wright, S., \& Allard, H. T. (2008). The role of insight teams in integrating diverse marketing information management techniques. European Journal of Marketing, 42(7/8), 836-851.

Floyd SW, Wooldridge B. 1999. Knowledge creation and social networks in corporate entrepreneurship: the renewal of organizational capability. Entrepreneurship Theory and Practice, Spring 23(3): 123-143.

Fuld, L.M. (1995). The new competitor intelligence: the complete resource for finding, analyzing and using information about your competitors, New York : John Wiley

Gammelgaard, J., \& Ritter, T. (2005). The knowledge retrieval matrix: codification and personification as separate strategies, Journal of Knowledge Management, 9, 133-143.

GIA, (2005). Competitive intelligence in large companies, global study, white paper.

Gilad, B. (2015). Companies Collect Competitive Intelligence, but Don’t Use It, Harvard Business Review, July 31.

Gomez, M. I., McLaughlin, E. W., \& Wittink, D. R. (2004). Customer satisfaction and retail sales performance: an empirical investigation, Journal of Retailing, 80, 265-278.

Gorla, N., Somers, T. M., \& Wong, B. (2010). Organizational impact of system quality, information quality, and service quality, The Journal of Strategic Information Systems, 19, 207-228.

Grant, R. M., \& Baden-Fuller, C. (2004). A knowledge accessing theory of strategic alliances, Journal of Management Studies, 41, 61-84.

Guanyu, Y., \& Guocan, Y. (2010, November). Knowledge Sharing Initiatives at the World Bank: Creating a Knowledge Bank”, In Information Management, Innovation 
Management and Industrial Engineering (ICIII), 2010 International Conference on (1, 83-87). IEEE.

He, W., Wu, H., Yan, G., Akula, V., \& Shen, J. (2015). A novel social media competitive analytics framework with sentiment benchmarks. Information \& Management, 52, 801-812.

Herrera-Viedma, E., Pasi, G., Lopez-Herrera, A. G., \& Porcel, C. (2006). Evaluating the information quality of web sites: A methodology based on fuzzy computing with words. Journal of the American Society for Information Science and Technology, 57(4), 538-549.

Herring, Jan P. (1992). The Role of Intelligence in Formulating Strategy”, Journal of Business Strategy, 13, 54-60.

Ho, L. A. (2008). What affects organizational performance? The linking of learning and knowledge management. Industrial Management \& Data Systems, 108(9), 1234-1254.

Hogarth, R.H., \& Makridakis, S. (1981). Forecasting and planning an evaluation”, Management Science, 27, 115-38.

Hooley, G.J., Greenley G.E., Cadogana J.W., \& Fahy J. (2005). The performance impact of marketing resources, Journal of Business Research, 58, 18 - 27.

Hughes, D. E., Le Bon, J., \& Rapp, A. (2013). Gaining and leveraging customer-based competitive intelligence: the pivotal role of social capital and salesperson adaptive selling skills, Journal of the Academy of marketing Science, 41, 91-110.

Ittner, C. D., \& Larcker, D. F. (1998). Are nonfinancial measures leading indicators of financial performance? An analysis of customer satisfaction, Journal of Accounting Research, 36, 1-35

Isik, Ö., Jones, M. C., \& Sidorova, A. (2013). Business intelligence success: The roles of BI capabilities and decision environments, Information \& Management, 50, 13-23. 
Israel Ministry of Economy and Industry major exporters list (2010).

Johns, P., \& Van Doren, D. C. (2010). Competitive intelligence in service marketing: A new approach with practical application, Marketing Intelligence \& Planning, 28, 551-570.

Katsikeas, S.C., Samee, S. \& Theodosious, M. (2006). Strategy fit and performance consequences of international marketing standardization, Strategic Management Journal, 27, 867-890.

Khairul, M.T., Saiful. F.M.Y., Abdul R.A. \& Ahmad N.M. (2008). Knowledge Management and Competitive Intelligence: A Synergy for Organizational Competitiveness in the KEconomy, Communications of the IBIMA 6, 5.

Kibbutz Industry Association (KIA) (2015). Enterprises' List: KIA 2015. Kibbutz Industry Association: Tel Aviv, Israel (Hebrew)

Kim, D. J., Ferrin, D. L., \& Rao, H. R. (2008). A trust-based consumer decision-making model in electronic commerce: The role of trust, perceived risk, and their antecedents, Decision Support Systems, 44, 544-564.

Kim, W. G., Ng, C. Y. N., \& Kim, Y. S. (2009). Influence of institutional DINESERV on customer satisfaction, return intention, and word-of-mouth, International Journal of Hospitality Management, 28, 10-17.

Knight, G., \& Cavusgil, S. (2004). Innovation, Organizational Capabilities, and the BornGlobal Firm, Journal of International Business Studies, 35, 124-141.

Kohli, A. K., \& Jaworski, B. J. (1990). Market orientation: the construct, research propositions, and managerial implications. Journal of Marketing, 1-18.

Korobilis-Magas, E. (2010), "Symbolic uses of export information: implications for export performance” (Doctoral dissertation, (C) Evagelos Korobilis-Magas). 
Kumar, V., Jones, E., Venkatesan, R., \& Leone, R. P. (2011). Is market orientation a source of sustainable competitive advantage or simply the cost of competing?, Journal of marketing, 75, 16-30.

Lackman, C., Saban, K., \& Lanasa, J. (2000). The contribution of market intelligence to tactical and strategic business decisions, Marketing Intelligence \& Planning, 18, 6 - 9.

Lapointe, L., \& Rivard, S. (2005). A multilevel model of resistance to information technology implementation, MIS quarterly, 461-491.

Leeflang, P. S., Verhoef, P. C., Dahlström, P., \& Freundt, T. (2014). Challenges and solutions for marketing in a digital era. European management journal, 32, 1-12.

Li, Y. M., \& Li, T. Y. (2013). Deriving market intelligence from microblogs, Decision Support Systems, 55, 206-217.

Lindell M.K., \& Whitney D.J. (2001). Accounting for common method variance in crosssectional research designs, Journal of Applied Psychology, 86, 114-121.

Makadok, R. (2001). Toward a synthesis of the resource-based and dynamic-capability views of rent creation. Strategic Management Journal, 22(5), 387-401.

Malhotra N.K., Kim S.S., \& Patil A. (2006). Common method variance in IS research: A comparison of alternative approaches and a reanalysis of past research, Management Science, 52, 1865-1883.

Margulies, B. (1997). Using competitive intelligence to bolster customer satisfaction at douglas aircraft company. National Productivity Review, 16(3), 75-80.

Mariadoss, B. J., Milewicz, C., Lee, S., \& Sahaym, A. (2014). Salesperson competitive intelligence and performance: The role of product knowledge and sales force automation usage, Industrial Marketing Management, 43, 136-145. 
Martín-de Castro, G. P., López-Sáez, P., \& Delgado-Verde, M. (2011). Towards a knowledge-based view of firm innovation: Theory and empirical research, Journal of Knowledge Management, 15, 871-874.

McCardle-Keurentjes, M. H., Rouwette, E. A. J. A., \& Vennix, J. A. (2008). Effectiveness of group model building in discovering hidden profiles in strategic decision-making, In Proceedings of the 2008 International System Dynamics Conference.

Menon, A. \& Varadarajan, P.R. (1992). A Model of Marketing Knowledge Use within Firms, Journal of Marketing, 56, 53-71

Moustaghfir, K. (2009). How knowledge assets lead to a sustainable competitive advantage: are organizational capabilities a missing link?, Knowledge Management Research \& Practice, 7, 339-355.

Murray, J. Y., Gao, G. Y., \& Kotabe, M. (2011). Market orientation and performance of export ventures: the process through marketing capabilities and competitive advantages, Journal of the Academy of Marketing Science, 39, 252-269.

Narver, J. C., \& Slater, S. F. (1990). The effect of a market orientation on business profitability. Journal of Marketing, 20-35.

Nasri, W. (2011). Competitive intelligence in Tunisian companies, Journal of Enterprise Information Management, 24, 53 - 67.

Olszak, C. M. (2014). An overview of information tools and technologies for competitive intelligence building: Theoretical approach, Issues in Informing Science and Information Technology, 11, 139-153.

Oreg, S. (2006). Personality, context, and resistance to organizational change, European Journal of Work and Organizational Psychology, 15, 73-101.

Pemberton, J. D., \& Stonehouse, G. H. (2000). Organisational learning and knowledge assetsan essential partnership, The Learning Organization, 7, 184-194. 
Prabhakaran, S., \& Satya, A. S. (2003), “An insight into service attributes in banking sector", Journal of Services research, Vol. 3, pp. 157-169.

Raghunathan, S. (1999). Impact of information quality and decision-maker quality on decision quality: a theoretical model and simulation analysis, Decision Support Systems, 26, 275-286.

Rakthin, S., Calantone, R. J., \& Wang, J. F. (2016). Managing market intelligence: The comparative role of absorptive capacity and market orientation, Journal of Business Research, 69, 5569-5577.

Ramírez, R., Österman, R., \& Grönquist, D. (2013). Scenarios and early warnings as dynamic capabilities to frame managerial attention, Technological Forecasting and Social Change, 80, 825-838.

Rapp, A., Agnihotri, R., \& Baker, T. L. (2015). Competitive intelligence collection and use by sales and service representatives: How managers' recognition and autonomy moderate individual performance, Journal of the Academy of Marketing Science, 43, 357-374.

Reinmoeller, P., \& Shaz, A. S. (2016). The Persistence of a stigmatized practice: A study of competitive intelligence, British Journal of Management, 27, 116-142

Rodenberg, R.M. (2007). Competitive intelligence and senior management. Eburaon Delft

Rollins, M., Bellenger, D. N., \& Johnston, W. J. (2012). Does customer information usage improve a firm's performance in business-to-business markets?, Industrial Marketing Management, 41, 984-994.

Rouach, D., \& Santi, P. (2001). Competitive intelligence adds value: Five intelligence attitudes, European Management Journal, 19, 552-559.

Russo, J. E., Carlson, K. A., Meloy, M. G., \& Yong, K. (2008). The goal of consistency as a cause of information distortion, Journal of Experimental Psychology: General, 137, 456-470. 
Saayman, A., Pienaar, J., De Pelsmacker, P., Viviers, W., Cuyvers, L., Mulleand, M.L., \& Jegers, M. (2008). Competitive intelligence: construct exploration, validation and equivalence, Aslib Proceedings, 60, $383-411$.

Sawka, K. A. (1996). Demystifying Competitive Intelligence, Management Review, 85, 47-

51.

Saxena, D., \& Lamest, M. (2018). Information overload and coping strategies in the big data context: Evidence from the hospitality sector. Journal of Information Science, 44(3), 287-297.

SCIP, The Society of Competitive Intelligence Professionals (2002). What is CI. Retrieved from https://web.archive.org/web/20030212145728/http://www.scip.org/ci/

Setia, P., Venkatesh, V., \& Joglekar, S. (2013). Leveraging digital technologies: How information quality leads to localized capabilities and customer service performance, Mis Quarterly, 37, 565-590.

Sher, P. J., \& Lee, V. C. (2004). Information technology as a facilitator for enhancing dynamic capabilities through knowledge management. Information \& management, 41, 933-945.

Singh, A., \& Beurschgens, A. (2006). Benchmark your CI capabilities using a self diagnosis framework, SCIP, 9, 22-25.

Sinkula, J. M. (1994). Market Information Processing and Organizational Learning. Journal of Marketing, 58, 35-45.

Slater, S. F., \& Narver, J. C. (2000). Intelligence generation and superior customer value, Journal of the Academy of Marketing Science, 28, 120-127.

Smith, L. C., \& Wong, M. A. (Eds.). (2016). Reference and Information Services: An Introduction: An Introduction. ABC-CLIO. 
Souchon, A. L., \& Diamantopoulos, A. (1999). Export information acquisition modes: measure development and validation. International Marketing Review, 16(2), 143-168.

Souchon, A. L., Diamantopoulos, A., Holzmüller, H. H., Axinn, C. N., Sinkula, J. M., Simmet, H., \& Durden, G. R. (2003). Export information use: a five-country investigation of key determinants, Journal of International Marketing, 11, 106-127.

Tarraf, P., \& Molz, R. (2006). Competitive intelligence at small enterprises, SAM Advanced Management Journal, 71, 24-34.

TASE - Tel Aviv stock exchange companies list (2015). retrieved from: http://maya.tase.co.il/indexEng.html\#/

Teece, D.J., Pisano, G., \& Shuen, A. (1997). Dynamic Capabilities and Strategic Management, Strategic Management Journal, 18, 509-533.

Teo, T. S. H., \& Choo, W. Y. (2001). Assessing the impact of using the internet for competitive intelligence, Information \& Management, 39, 67-83. Retrieved from www.scopus.com

Toften, K., \& Rustad, K. (2005). Attributes of information quality of export market assistance: an exploratory study, European Journal of marketing, 39, 676-695.

Torres, A., \& Tribó, J. A. (2011). Customer satisfaction and brand equity. Journal of Business Research, 64, 1089-1096.

Torres, R., Sidorova, A., \& Jones, M. C. (2018). Enabling firm performance through business intelligence and analytics: A dynamic capabilities perspective. Information \& Management, 55(7), 822-839

Ulijn, J., \& Brown, T. E. (2004). Innovation, entrepreneurship and culture, a matter of interaction between technology, progress and economic growth? An introduction, Innovation, entrepreneurship and culture: The interaction between technology, progress and economic growth, 1-38. 
Vaughan, L. \& You, J. (2011). Exploring web data for competitive intelligence. The case of the femtocell sector, Advances in Competitiveness Research, 19, 37-49. http://search.proquest.com/docview/886530197?accountid=14544

Vijande, L.S, Sanzo-Pérez, M., Oviedo, S., Gutiérrez, J.A.T., \& García Rodríguez, N.C. (2012). Marketing Capabilities Development in Small and Medium Enterprises: Implications for Performance, Journal of CENTRUM Cathedra, 5, 24-42.

Vyas, R., \& Souchon, L.A. (2003). Symbolic use of export information, International Marketing Review, 20, $67-94$.

Walters, B. A., Priem, R. L., \& Shook, C. L. (2004). Small business manager scanning emphases and the dominant logic of the business-level strategy, Journal of Small Business Strategy, 15, 19-32.

Webb, J. W., Ireland, R. D., Hitt, M. A., Kistruck, G. M., \& Tihanyi, L. (2011). Where is the opportunity without the customer? An integration of marketing activities, the entrepreneurship process, and institutional theory. Journal of the Academy of Marketing Science, 39(4), 537-554.

Williams, P., \& Naumann, E. (2011). Customer satisfaction and business performance: a firmlevel analysis, Journal of Services Marketing, 25, 20-32.

Wilson, E.J., \& Lilien, G.L. (1992). Using Single Informants to Study Group Choice: An Examination of Research Practice in Organizational Buying, Marketing Letters, 3, 297-305.

Wright, S., \& Calof, J. (2006). The quest for competitive, business and marketing intelligence, European Journal of Marketing, 40, 453 - 465.

Xu, K., Liao, S. S., Li, J., \& Song, Y. (2011). Mining comparative opinions from customer reviews for Competitive Intelligence, Decision Support Systems, 50, 743-754. 
Yin, C. Y. (2015). Measuring organizational impacts by integrating competitive intelligence into executive information system, Journal of Intelligent Manufacturing, 1-15.

Zheng, W., Yang, B., \& McLean, G. N. (2010). Linking organizational culture, structure, strategy, and organizational effectiveness: Mediating role of knowledge management, Journal of Business Research, 63, 763-771.

Zou, S., Taylor, C. R., \& Osland, G. E. (1998). The EXPERT scale: A cross-national generalized export performance measure, Journal of International Marketing, 6, 37-5 


\section{Figure 1 - Research Model}

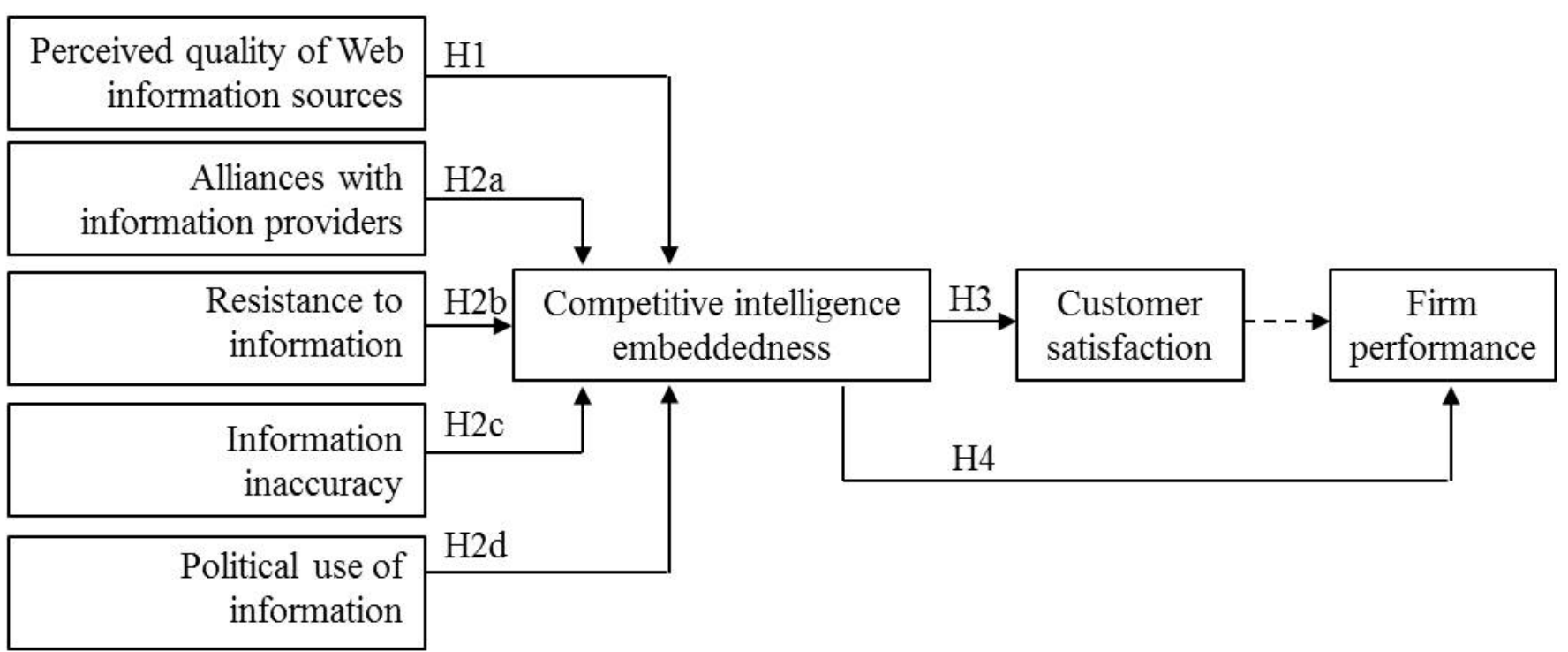


